\title{
ESPAÇOS CORPORATIVOS E APROPRIAÇÃO: NOVAS ÁREAS LIVRES NA METRÓPOLE PAULISTANA
}

\author{
SATO, Marissol Yuka \\ Estudante de graduação da Faculdade de Arquitetura e Urbanismo da Universidade de São Paulo; pesquisa \\ de iniciação científica realizada através da Fapesp. E-mail: msolbr@yahoo.com.br
}

\section{RESUMO}

O crescimento caótico dos grandes centros urbanos implica na crescente demanda por espaços livres, importante fator para a qualidade de vida da população. Até o final da modernidade, a gestão de espaços livres das cidades coube tradicionalmente ao poder público. Entretanto, no contexto sócio-econômico e cultural das metrópoles contemporâneas, não existe uma clara distinção dos papéis de cada agente na construção do espaço livre, tampouco uma clara definição do próprio conceito de espaço público. Atualmente, iniciativa pública e privada dividem espaço na criação e gestão dos espaços livres oferecidos à população. É preciso refletir sobre o papel de cada agente; até onde vai a atuação do poder público na mediação desses processos junto à interesses privados. Em São Paulo, (maior metrópole brasileira), encontramos inúmeros exemplos desse fenômeno nas cidades: a praça do complexo Brascan Century Plaza no Itaim, a praça da Rua Amauri (premiado na última Bienal de arquitetura de São Paulo), o Centro empresarial Itaúsa, ou a praça co complexo de edifícios Cetenco Plaza, na Avenida Paulista.

O que leva as pessoas a fazerem uso de um espaço da forma que o fazem? Porque certos espaços corporativos apresentam uma vitalidade que muitos espaços públicos não têm? Tais questionamentos podem contribuir para o debate da qualidade dos espaços livres existentes nas cidades e mesmo para a importância destes a sociedade. A compreensão do cenário pós-moderno e a abordagem de questões sociológicas e mesmo psicológicas são de grande relevância para esse debate.

\section{Palavras-chave: Espaços corporativos, apropriação, pós-modernidade, psicologia ambiental.}

\begin{abstract}
The chaotic growth of great urban centers implies in an increasing demand for open spaces as well, important factor in the population's quality of life. Until the end of modernism, public power was traditionally responsible for the management of open spaces in cities. However, in the context of the contemporary metropolis' socio-economic and cultural scenery there is not a clear distinction between the roles of each agent in the construction of open spaces; neither a clear definition of public space itself. Nowadays, public and private initiatives share space in building and managing open spaces offered to the citizens. It's important to reflect over the role that each agent holds. Where public administration stands in the negotiations with private interests? In São Paulo9 the largest Brazilian metropolis) can be found countless examples of this phenomenon in urban spaces: the plaza of the Brascan Century Plaza in Itaim, the pocket park on Amauri Street (awarded in the last Bienal de Arquitetura de São Paulo), Centro Empresarial ltaúsa, or the plaza around the Cetenco Plaza complex buildings, on Paulista Avenue. What leads people to enjoy a space the way they do? Why some corporative spaces have vitality that many public spaces don't? These questions may contribute to the debate over the quality of open spaces in contemporary cities and even over the importance that they hold to society. The comprehension of a post-modern scenery and the approach of sociological and psychological issues are very relevant to the presented debate.
\end{abstract}

Key words: Corporative spaces, appropriation, post-modernism, environmental psychology. 


\section{Introdução}

Focando o caso da cidade de São Paulo, foi possível identificar diversos casos que indicam uma tendência da iniciativa privada de ceder espaços livres para usufruto da população e/ou gerir e cuidar de espaços públicos como praças, parques e canteiros. Ainda que busquem também interesses próprios, é preciso ressaltar a importância dessas ações pontuais na cidade. A análise de tal tendência, observada já há décadas em grandes cidades, a exemplo das norteamericanas, levanta ainda questões como a natureza da participação da iniciativa privada na construção do ambiente urbano, os deveres do poder público e os direitos da população de usufruir os espaços livres da cidade.

O tema estudado não é recente, entretanto é limitada a quantidade de material existente no país sobre o assunto, especialmente quando aplicado à área de arquitetura e urbanismo. Podese indicar os estudos de APO (Avaliação Pós-Ocupacional) como uma das poucas referências nacionais ao estudo do espaço construído. Atualmente ele é utilizado principalmente para diagnosticar problemas em edifícios existentes que indicariam a necessidade de alguma reforma para optimizar seu uso.

O fenômeno dos shoppings centers sem dúvida teve grande influência na configuração urbana de São Paulo, bem como no cotidiano da população, tendo sido alvo de estudos ambientais e sociológicos. A popularização desses edifícios determinou declínio de tradicionais ruas de compras, como a Rua Augusta, por exemplo. A implantação de um SC em um local acarreta várias conseqüências, como a valorização imobiliária da região ao redor e a sobrecarga da infra-estrutura urbana. Mais do que isso, ele influi nos hábitos das pessoas e transforma o seu cotidiano. A difusão do SC na cidade é um sintoma de alterações nos padrões de comportamento da população. Em palestra recente que discutiu a relação entre espaços públicos e espaços privados, o arquiteto Gianfranco Vanucchi, um dos responsáveis pelo projeto do Brascan Century Plaza, destacou o fenômeno dos SC urbanos como sendo tipicamente brasileiro. Nos Estados Unidos, onde nasceu, os SC ficam às margens de rodovias, longe dos centros urbanos movimentados. $\bigcirc$ arquiteto ainda atenta para referências que remetem a uma praça tradicional de convívio nesses projetos. Cita o caso do Shopping Center Iguatemi, onde "tenta-se reproduzir o pequeno espaço bucólico do interior, sem carros. Buscam-se simbologias que tentam transformá-lo em uma praça a céu aberto."

A palestra citada faz parte de um ciclo de debates intitulado Fazendo a Cidade, onde se discutem os problemas enfrentados por arquitetos e urbanistas ao desenvolver projetos nas grandes cidades, além de novos caminhos e possibilidades. Diante dos diversos projetos apresentados na palestra, e de tantos outros que podemos observar na cidade atualmente, não se pode negar a tendência de integrar espaço privado e público, na busca pela melhora da qualidade espacial da cidade. $O$ termo gentileza urbana tem sido difundido na arquitetura, referindo-se a projetos privados que agregam valor ao espaço público. Para esses profissionais é revigorante observar a substituição de muros altos por recuos ajardinados, espaços de estar e locais de contemplação em projetos recentes. Entretanto, reverter o processo crescente de enclausuramento das construções nas últimas décadas se mostra uma tarefa difícil, que exige uma transformação que vai muito além da esfera do projeto e planejamento urbano.

A carência de estudos na área vem reforçar a necessidade de pesquisas sobre o tema. $\bigcirc$ reconhecimento da importância de espaços livres na cidade, especialmente nas áreas adensadas, bem como as possibilidades que parcerias entre iniciativa privada e poder público geram, deveriam determinar o estabelecimento de uma política específica. Assim como o Midtown Zoning contribuiu para o surgimento de diversos espaços privados de acesso público a partir da década de 80 em Nova York, São Paulo poderia se beneficiar de forma análoga. Obviamente tal legislação exigiria estudo cuidadoso para sua aplicação. Entretanto existe um mercado que 
responderia bem a esse processo, uma vez que existe grande interesse em adquirir o Direito de Construir que possibilita maiores gabaritos. Se bem estruturada, resultaria em situação benéfica para todos.

\section{Paisagem urbana pós-moderna}

Público ou privado? Tratadas como esferas antagônicas, sua relação determinou muitos debates no campo do desenho urbano nas últimas décadas. Mais do que simplesmente demarcação de territórios ou estabelecimento de propriedade, a contraposição público / privado está enraizada em nossa cultura, afetando comportamentos e influenciando a construção do espaço urbano.

Assim, as relações entre público e privado são mais que simples oposição, constituindo uma relação mais complexa no cotidiano da cidade. No caso de São Paulo assistimos a um processo de segregação espacial dessas duas esferas, que vem se acentuando nas últimas décadas. Condomínios fechados e edifícios de apartamentos se tornam feudos isolados. Shopping centers se tornam espaço de interação social de grupos homogêneos. Estas pessoas se locomovem entre trabalho, residência e lazer de automóvel. Até mesmo no transporte nota-se um sintoma deste fenômeno. $\bigcirc$ uso de insufilm, uma película de proteção nos vidros dos automóveis, impede a vizualização do interior destes. Todos esses fatores demonstram um afastamento do convívio e espaço público. Isto não representa apenas um abandono do espaço público, mas também uma tomada deste e sua transformação em ambiente de consumo. Há quem afirme que passamos por um processo de privatização da vida pública, onde o cidadão se torna consumidor, e a paisagem urbana é inundada por anúncios publicitários nas mais diversas mídias.

Essa transformação das cidades em produto de consumo visual não é exclusividade nossa, mas um fenômeno que atinge os centros urbanos mundias como um todo. Muitos identificam esse fenômeno como sintoma de que passamos por um processo de ruptura, adentrando em novo momento histórico: a pós-modernidade. $\bigcirc$ tema está em debate há décadas, sem ter chegado a um consenso sobre a autenticidade do fato: estamos de fato vivendo a pós-modernidade? David Harvey descreve a pós-modernidade como um "campo minado de noções conflitantes", e, assim como outros teóricos, é muito cauteloso ao empregar o termo. Mas fica a questão: se a pós-modernidade não representa de fato uma superação de questões trazidas pela modernidade, porque essa idéia se disseminou?

A arquitetura talvez tenha sido o campo onde o pós-moderno foi mais amplamente divulgado. Sendo o objetivo primordial da cultura pós-moderna a oposição à modernidade, é fácil compreender porque a arquitetura foi um dos caminhos mais penetrados. $\bigcirc$ modernismo gerou os produtos mais paupáveis da ideologia moderna - cidades construídas ou reestruturadas segundo premissas funcionais surgiram por todo o mundo. $O$ conhecimento tecnológico foi instrumento pare que a arquitetura modernista estabelecesse uma nova ordem do espaço urbano. $O$ tecido urbano foi destruído, e em seu lugar torres sobre pilotis se distanciam do espaço urbano tradicional; a escala do pedestre é substituída pela escala do automóvel. A difusão de novas tecnologias, como o carro, o elevador, as estruturas de aço, permitem essas alterações radicais na paisagem. A destruição de cidades européias pela guerra forneceu um vasto laboratório para as experiências do modernismo. Entretanto a necessidade de renovação do espaço urbano fez com que seus ideais alcançassem cidades por todo o mundo. Os impactos negativos da lógica modernista na cidade gerou uma reação contra o movimento. Seus críticos denunciam a ingenuidade na crença de que um novo desenho urbano bastasse para criar nova ordem social. $\mathrm{Na}$ década de 60 assistimos o crescimento de movimentos contraculturais e antimodernistas que foram as raízes do pós-modernismo que emergiu no início da década de 70, ainda que de forma incoerente. Um dos fatos mais marcantes que anunciaram o fim do modernismo foi a implosão do conjunto habitacional Pruitt-Igoe, em Saint Louis nos Estados Unidos, em julho de 
1972. Premiado pela União Internacional dos Arquitetos, o projeto se mostrou um fracasso social, restando como única solução sua destruição. Essa insatisfação geral com o modernismo gerou a consciência de ruptura apontada por teóricos, e lançou as bases do pós-modernismo.

Apesar de tudo, não se pode negar o valor da contribuição dos arquitetos modernos. Em seu projeto estético e político, o modernismo combatia o ecletismo do final do século XIX, empregando traços simples que, conforme afirmavam, estabeleciam uma estética universal. Por outro lado, ao suprimir ornamentos e adornos, permitia o uso de recursos industriais para a produção em massa de componentes construtivos e tantos outros bens. $O$ emprego das novas tecnologias e a produção em massa pela indústria possibilitou a rápida reconstrução de cidades no pós-guerra, o que não parecia viável de qualquer outra forma. Assim, o ideal moderno tem o mérito de responder à grande demanda habitacional e colaborar para a recuperação econômica.

pós-modernismo contraria preceitos da arquitetura modernista. Enquanto a última distanciase do contexto urbano, impondo uma estética universal e destruindo os vernáculos e estilos tradicionais através de um grande plano ordenador do espaço urbano, o pós-modernismo procura integrar-se na paisagem fragmentada das cidades contemporâneas, respeitando a especifidade dos estilos locais, mas sem rejeitar a contribuição de outras linguagens, o que se adequa ao seu perfil eclético. A arquitetura pós-moderna foca a população, e se identifica com a cultura de massas, mantendo uma relação próxima com a vida diária, buscando uma integração com ela.

O processo de enobrecimento, ou gentrificação como é comumente referido, amplamente estudado por Sharon Zukin, implica em uma apropriação cultural e espacial de uma paisagem vernacular, impondo uma visão própria àquele local. Determinadas partes da cidade tornam-se produto de consumo visual. Em São Paulo, a revitalização do centro antigo conta com visões dissonantes. Enquanto muitos planejadores urbanos apostam no incentivo a habitação de média e baixa renda, instituições privadas têm investido em outros usos, como centros culturais e recuperação de edifícios antigos para instalação do setor terciário. Nas últimas décadas, a população de baixa renda se locomoveu para as áreas periféricas da cidade, gerando uma demanda de extensão da infra estrutura urbana. Do ponto de vista prático, a atração dessa população de volta para o centro aliviaria tal demanda, beneficiando a municipalidade. Por outro lado, o centro tem um forte apelo emocional enquanto lugar, a história da cidade está impressa em suas ruas, largos, ladeiras, seus edifícios, além disso, goza de ótima infra estrutura urbana. Esses fatores o tornam atrativo para o mercado, suscetível a um processo de enobrecimento, com o qual o estabelecimento de habitações de baixa renda não é compatível pela lógica tradicional.

\section{Paisagem urbana}

Na prática, nossa sociedade é regida por relações de mercado, ordenada por um poder público. Corporações e instituições privadas têm grande influência na construção do espaço urbano. Entretanto, a dicotomia público e privado delimita campos de ação e espaços na cidade. Até o final da modernidade, criação gestão de espaços livres coube tradicionalmente ao poder público. Entretanto a pós-modernidade, apresenta novas dinâmicas, onde não é clara a distinção do papel de cada agente na construção do espaço livre urbano, tampouco do próprio conceito de espaço público.

262 A relação entre espaço público e privado não é um tema recente, tendo sido abordado sob várias óticas. Ao avaliar espaços privados que apresentam uma continuidade com os caminhos da cidade, é difícil não se lembrar do Conjunto Nacional (David Libeskind, 1952-58) na Avenida Paulista. Na realidade a obra é um dos exemplos mais bem sucedidos de edifício-cidade, 
conceito muito popular nos anos 50, época do boom imobiliário paulistano. Embora ainda existam diversos desses edifícios em São Paulo, a maioria se encontra em estado de abandono. O próprio Conjunto Nacional passou por uma fase decadente, sendo recuperado graças a uma administração bem gerida. $O$ empreendimento ambicioso ocorreu em uma época em que ainda havia diversos palacetes na Avenida Paulista, direcionado portanto, a uma elite financeira.

Historicamente, em São Paulo, os rumos da cidade sempre foram guiados por interesses privados. Esse aspecto se reflete claramente no desenho urbano: rios retificados, córregos canalizados, áreas impróprias ocupadas, verticalização que sobrecarrega a infra-estrutura urbana disponível. Desde a expansão da economia cafeeira no século XIX, a cidade vem crescendo em um ritmo descontrolado sob o olhar de um poder público permissivo, resultando na atual situação, onde grande parte da população vive em condições insatisfatórias. Atualmente, ainda é clara a prioridade dada a interesses privados na construção da paisagem urbana em detrimento de interesses da população

O impacto da atuação da iniciativa privada sobre o desenho da cidade foi determinante em São Paulo. Independente das motivações dos gestores de espaços corporativos, aspectos como propriedade legal e apropriação levantam questões polêmicas. Os usuários têm o direito de opinar sobre a gestão do espaço? Como administrar interesses de ambas as partes? Cabe ao poder público interferir nessa mediação? Muitas vezes a negociação entre as diferentes instâncias determina rumos que nem sempre correspondem ao melhor interesse da cidade.

Países emergentes freqüentemente buscam referências econômicas, políticas e culturais no exterior. Inserir modelos sem considerar o devido contexto local, como o fez o estilo internacional, se mostrou uma estratégia muitas vezes nociva. Questões de identidade local e global são tratadas de diferentes formas pelos profissionais. Atualmente é possível observar por São Paulo, edifícios e espaços projetados com o intuito de vender uma imagem de cidade cosmopolita. Dos residenciais em estilo clássico aos edifícios de escritórios em aço e vidro, a construção de uma estética artificial transforma o repertório e a percepção das pessoas. $\bigcirc$ mesmo conceito pode ser empregado na construção dos espaços livres.

O emprego de determinados materiais, a implantação de determinados usos, o modo como se dá a gestão do espaço, todos esses aspectos transmitem mensagens, captadas consciente ou inconscientemente pelas pessoas. A vivência de cada usuário, sua formação cultural, funciona como uma espécie de filtro, que leva a diferentes percepções do ambiente, implicando em diferentes formas de apropriação. No caso de espaços desenhados para a elite, é comum o uso de materiais nobres combinado com uma manutenção ostensiva. Argumenta-se que esses espaços "nobres" transmitem sinais que determinam a quem eles são direcionados, intimidando, por vezes, usuários de outros grupos sociais. Seriam sinais reconhecidos pelas pessoas, às vezes em nível subconsciente. Esses sinais são utilizados de várias formas. Por exemplo, o cercamento de uma praça pública em bairro residencial pode inibir a entrada de transeuntes, mesmo que estes se deparem com um portão aberto.

Espaços que atraem uma população de diversas classes sociais, idades e interesses, são culturalmente mais ricos, democráticos. Sem diminuir a necessidade de locais como praças de áreas residenciais, que contribuem para a convivência entre moradores de suas ruas, as cidades também necessitam de espaços onde os diferentes grupos que formam a sociedade possam interagir.

\section{Casos representativos}

A busca de referências para melhor compreensão da questão dos espaços livres corporativos em São Paulo revelou uma carência de material, dado o surgimento relativamente recente desses espaços. Da mesma maneira, referências sobre estudos de apropriação de espaços livres na cidade são poucas. Sobre a questão específica da apropriação de espaços livres urbanos, 
existe um rico material fornecido por estudos no exterior, especialmente nos Estados Unidos. Autores como William Whyte e Clare Cooper Marcus apresentam análises detalhadas de estudos de apropriação de praças. Explica-se a existência de extensa bibliografia norte americana referente ao assunto pelo fato de suas cidades terem encarado uma crise do espaço livre desde a metade do século XX. Provida de inúmeros espaços livres, Manhattan, em Nova York, sempre foi alvo comum para estudos nesse campo. Assim, embora a metodologia aplicada se apóie em referências válidas, é preciso compreender a diferença na essência desses espaços com os nossos. Os espaços livres nos centros urbanos americanos foram fruto de uma demanda real para aliviar o crescente tráfego de pedestres.

"No final dos anos 50 e início dos 60 do século passado, o caos causado pelo intenso tráfego de pedestres nas calçadas de áreas centrais de cidades norte americanas era visível. Diversas corporações com edifícios de escritórios a serem implantados em Manhattan sacrificaram área de seus lotes para criar algumas das primeiras praças de pedestres modernas, a exemplo da Lever House (Gordon Bunshaft, 1951) e Seagram Building (Mies van der Rohe, 1957)." (Marcus, pp.13)

Profissionais preocupados com essas questões procuraram meios legítimos de reivindicar espaços livres para a população. Logo surgiram os primeiros instrumentos de legislação urbana voltados para implementação de espaços que aliviassem a estressante tarefa de caminhar por calçadas superlotadas. Por se tratar de um instrumento novo, sem precedentes no planejamento urbano, foi preciso aperfeiçoá-lo, aprendendo com os problemas observados nos primeiros espaços construídos após sua criação.

"Tão logo as novas leis de zoneamento entraram em validade, quase todo edifício grande novo edifício em Manhattan tirou vantagem do sistema de bônus. Já em 1970, só na milha quadrada central de Manhattan - equivalente a 640 acres - havia mais de 11 acres de praças públicas para pedestres - cerca de $2 \%$ - em solo privado, e mais de 2 acres de espaço ornamental, consistindo de trabalho paisagístico e fontes. (...) Infelizmente os projetistas, tendo poucas referências nos Estados Unido, caiu na armadilha de 'se espaço aberto é bom, mais espaço aberto é melhor'. Praças monumentais foram assim construídas, totalmente desconectadas da escala humana, e freqüentemente desprovida de atividades humanas." (Marcus, pp.13)

"Um novo sistema chamado Midtown Zoning foi estabelecido em 1982. Foram estabelecidas as condições necessárias para que os espaços abertos oferecidos fossem aprovados para o Bonus System (Sistema de Bônus), como nível de insolação, escala do espaço, acesso, iluminação, sinalização, etc." (Process Architecture, pp.78)

Embora as referências de estudos de apropriação sejam basicamente americanas, existem casos de espaços livres corporativos em toda a parte. Em específico, foram encontrados vários casos no Japão, onde o conceito de pocket park foi bastante difundido. Esses pequenos espaços livres distribuídos pela cidade foram fruto, no caso de Nova York, da legislação urbana citada. Exemplos representativos de pocket parks são o Paley Park e o Greenacre Park, ambos em Manhattan. A revista Process Architecture apresenta o fenômeno do pocket park como a transposição de um conceito de espaço que sempre existiu naturalmente na ocupação humana para os densos centros urbanos. Esses pequenos oásis surgiram para suprir a necessidade das pessoas de locais íntimos e acolhedores nas cidades.

No Japão, a renovação do distrito de Shinjuku, em Tóquio, desde os anos 70, determinou o surgimento de diversos pocket parks artificiais. Oferecidos como espaços livres na base de arranha-céus, surgem sob orientação administrativa de empreendedores, ao invés de troca de benefícios por meio de instrumentos de legislação urbana. (Process Architecture) Da mesma forma que ocorre em São Paulo, esses espaços são oferecidos como um benefício à população, ao mesmo tempo que incorporações e instituições se beneficiam do marketing gerado. 


\section{Brascan Century Plaza}

O uso intenso observado na praça do Brascan Century Plaza surpreende, não apenas pela quantidade de pessoas que atrai, como pela variedade - pessoas de diversas idades, em diversas atividades e de diferentes classes sociais. Casos como este são pouco comuns na cidade, especialmente sob uma configuração de espaço livre, o que instigou a investigação do tema. Projetado pelo escritório Königsberger Vannuchi Arquitetos Associados, o Brascan Century Plaza configura um complexo de uso diversificado, cuja praça térrea foi projetada pelo paisagista Benedito Abbud. Foi interessante observar aqui como o caráter do espaço é modificado ao longo do tempo pelas formas de apropriação. Diferentes momentos correspondem a diferentes aspectos da praça. Em dias de semana, o horário de almoço a transforma em uma grande praça de alimentação, enquanto que o período da tarde e noite fazem dela local de lazer do público em geral. Em fins de semana, predomina um público de classe média e alta, vindo de bairros próximos, a lazer. Outros usuários simplesmente relaxam, contemplam o espaço ou lêem. Em meio a esses usuários, moradores locais, que caminham curtas distâncias até a praça, a vêem como local de interação social, onde encontram amigos e pessoas do bairro.

A diversidade de usuários não representa necessariamente se tratar de um espaço completamente democrático. Regras sociais informais determinam o comportamento das pessoas em espaços comuns, possibilitando a convivência entre os diferentes indivíduos. Diferentes ambientes implicam em diferentes comportamentos e diferentes formas de apropriação. Aqui, o gestor do espaço impõem uma série de regras, comuns em locais como shoppings, mas não em praças públicas. Apesar desse "policiamento" no uso do espaço, muitos usuários se satisfazem com a sensação de segurança. Assim, alguns direitos são sacrificados em troca de outros benefícios.

Um ponto de interesse na análise desse espaço foi o impacto da estética na percepção do usuário e por conseguinte na apropriação do espaço. Seria a estética um elemento inibidor ou motivador do uso de uma praça? A estética é parte importante do aspecto do ambiente, da imagem que ele projeta. Entretanto essa imagem envolve também questões de manutenção e conservação. De fato, as pessoas associam sensações agradáveis à espaços bem cuidados e "bem frequentados" - implicando na presença ou ausência de usuários com os quais cada indivíduo prefere compartilhar o espaço. Entretanto, dois ambientes bem mantidos e geridos, com configurações espaciais semelhantes podem transmitir mensagens bem diferentes através da estética. Usos adjacentes como cinema e restaurantes mais caros, bem como a região em que se insere parecem ter maior influência na atração de determinado público, levantando a questão da relevância dos usos próximos. No caso do Brascan, restaurantes, cinemas, cafés, hotéis e escritórios, cada uso foi programado focando uma população específica - pessoas de classe média e alta que trabalham e/ou moram na região. $O$ ambiente é cuidadosamente montado com referências direcionadas ao público-alvo. Aqui, surpreende que o desenho da praça contraponha e ao mesmo tempo complemente o ambiente de consumo criado, convidando usuários diversos. São consumidores do espaço, pois ainda que o uso da praça não implique em um consumo real, ele implica em um consumo visual.

A grande maioria dos usuários no Brascan trabalha ou mora nos arredores. Tendo conquistado uma certa familiaridade com a praça, fazem dela parte de seu cotidiano. Outros vem de bairros próximos como Jardim Europa e Jardim Paulista para passear. $O$ cinema é um elemento que atrai pessoas de bairros mais distantes, as quais acabam por utilizar a praça também. Podese identificar dois perfis dessa praça: características tanto de uma praça de bairro como de um local de significato abrangente na cidade se compatibilizados em um mesmo espaço. No Brascan é possível encontrar simultaneamente pessoas que vem de locais distantes na cidade para se encontrar, e moradores dos prédios vizinhos que se encontram cotidianamente na praça para "bater-papo". 


\section{Considerações finais}

Este artigo tem como base uma pesquisa realizada através da Fapesp. Tal pesquisa procura acima de tudo chamar a atenção para um tema negligenciado por profissionais do campo de projeto e desenho urbano. Incluindo nesse grupo, pesquisadores e pessoas ligadas ao ensino da arquitetura. A busca por referências bibliográficas revelou uma vasta quantidade de referências internacionais sobre a avaliação da apropriação do espaço livre, entretanto, no Brasil, o tema é muito pouco abordado. Boa parte do material encontrado é fruto de pesquisas em áreas como antropologia e psicologia. Na área de arquitetura e urbanismo, a principal fonte de referência foram os estudos de APO desenvolvidos principalmente por Sheila Walbe Ornstein. A quantidade limitada de material na área não é um indício de desinteresse pelo tema do uso dos espaços livres, mas sim, um desconhecimento dos meios de avaliação e de suas possibilidades.

O desejo por investigar a apropriação de espaços livres corporativos na cidade nasceu da mesma inquietação observada em vários projetistas de espaços divididos (ou compartilhados) por essas duas esferas de domínio - público e privado. Esses dois termos, comumente percebidos como antagônicos, na prática não representam opostos. $O$ contraste rígido com o qual essas esferas são encaradas pela população, por si só contribui para problemas observados no uso de espaços livres urbanos. A complexidade das relações sociais e espaciais na paisagem urbana pós-moderna não permite posturas rígidas baseadas em modelos ultrapassados. Reavaliar o papel de cada agente na construção do ambiente da cidade se tornou uma premissa básica. Que obrigações corporações que investem na construção e manutenção de ambientes de acesso público têm para com a população? Qual o papel do poder público enquanto mediador dessas relações? Que direitos os cidadãos podem reivindicar no uso desses espaços? Não existem respostas à essas questões, mas elas devem abrir o debate do espaço livre urbano. Se a análise é instigada pelos indícios de uma nova forma de perceber e fazer a cidade, ela também procura instigar a reflexão sobre o tema, e suas implicações no cotidiano do indivíduo contemporâneo.

\section{Bibliografia}

FRÚGOLI Jr., Heitor. A questão da centralidade em São Paulo: $\bigcirc$ papel das associações de caráter empresarial. Revista de sociologia e política, n. 16, p. 51-66, 2001.

GALENDER, Fany Cutcher. Nova York: Uma experiência de desenhos dos espaços livres urbanos. Paisagem e Ambiente: Ensaios, São Paulo: FAUUSP, n. 8, 1995.

HARVEY, David. Condição pós-moderna. São Paulo: Loyola, 1994.

JACOBS, Jane. Morte e vida de grandes cidades. Martins Fontes: São Paulo, 2001.

MARCUS, Clare Cooper; FRANCIS Carolyn. People places: Design guidelines for urban open space. Nova York: Van Nostrand Reinhold, 1990.

ORNSTEIN, Sheila; BRUNA, Gilda; ROMÉRO, Marcelo. Ambiente construído e comportamento: A avaliação pós-ocupação e a qualidade ambiental. São Paulo: Studio Nobel/FAUUSP/FUPAM, 1995.

PINTAUDI, Silvana Maria; FRÚGOLI Jr., Heitor. Shopping centers - Espaço, cultura e modernidade nas cidades brasileiras. São Paulo: Unesp, 1992.

PROCESS ARCHITECTURE. Pocket Parks, Tóquio-Japão: Process Architecture Publishing, n. 78, 1988.

VANUCCHI, Gianfranco; GASPERINI, Gian Carlo; AFLALO, Roberto. Espaços públicos x espaços privados, Ciclo de debates: Fazendo a cidade. São Paulo: Instituto Tomie Ohtake, 2005. da diferença. Campinas: Papirus, 2000.

ZUKIN, Sharon. The culture of cities. Cambridge: Blackwell, 1995. 